\title{
The evolution of architectural forms through computer visualisation: muqarnas example
}

\author{
Mohammad A Yaghan \\ German Jordanian University \\ P.O. Box 142042 -11814 Amman Jordan \\ myaghan@muqarnas.org
}

\begin{abstract}
Computers have been used for the reconstruction of historical buildings in architecture and archaeology in order to visualise forms that existed before. The goal of this paper is to push further the evolution of an architectural form of a high cultural significance in the history of Islamic architecture; muqarnas.
\end{abstract}

\begin{abstract}
Muqarnas is a three-dimensional form whose visual function is to provide the gradual transition between two levels, two sizes, and or two shapes. It evolved over a period of eight centuries and, later, was neglected. Nowadays, it is being copied and introduced into the architecture of the Islamic world, but only as a rigid copy and not as a living evolving form. A long research on the computerisation of muqarnas over the last two decades aimed at pushing further the evolution of this form into new possibilities.
\end{abstract}

The basic theory behind this research revolves around typology. Defining a type requires stating all its perceived qualities, both of fixed values 'characteristics', and of variable values 'attributes'. Creating new forms would be, then, giving new values for the attributes. A true evolution of the form happens when a characteristic is turned into an attribute and given new values. When this theory was applied in muqarnas research at many levels, it produced many new evolutionary steps which will be presented. The theory could be applied in other fields where there is a need for the evolution of traditional forms.

Muqarnas. Typology. Islamic architecture

\section{INTRODUCTION}

Muqarnas is a three-dimensional form whose visual function is to provide the gradual transition between two levels, two sizes, and or two shapes. Muqarnas consists of orderly horizontal layers of small 'unitsurfaces', the layers are stacked one on top of another, connected via their base- and top- 'layerlines'. The base layer-lines of a layer and the top layer-lines of the layer below are either identical or separated by 'layer-joints'. Any horizontal gaps inbetween layer-lines of same height (like stars) are filled by 'roof-patches'. The Roof-patches, the unitsurfaces, and the layers are created according to a two-dimensional-pattern-plan (2DPP) with clearly defined boundaries. Figure 1 shows the basic parts of the muqarnas.

As a form, Muqarnas is the creation of Islamic architecture, and along with Arabic calligraphy is considered as basic determinants of Islamic art. For more information on muqarnas please refer to (Yaghan, 2001a; Yaghan, 2005b; BehrensAbouseif 1993).
Muqarnas has a certain degree of complexity that varies from one muqarnas form to another depending on the two-dimensional pattern plan that it is created upon. Most muqarnas drawings were only plans that needed a great deal of experience to decode into three-dimensional forms. Accordingly, computers are very useful tools that help producing the actual form for purpose of visualising and improving design quality. However, the computer-muqarnas-drafting is still a tedious job.

Recently, there were three programs (written by the current author) that managed to create muqarnas and save the user a great deal of technical knowledge and working hours.

These programs were not meant to create the traditional forms only, but also were new evolutionary stages for muqarnas. New forms were created, and new visions were perceived. 
This paper attempts on explaining the theory behind these programs as an example on how to use computers to evolve traditional forms and create the new.

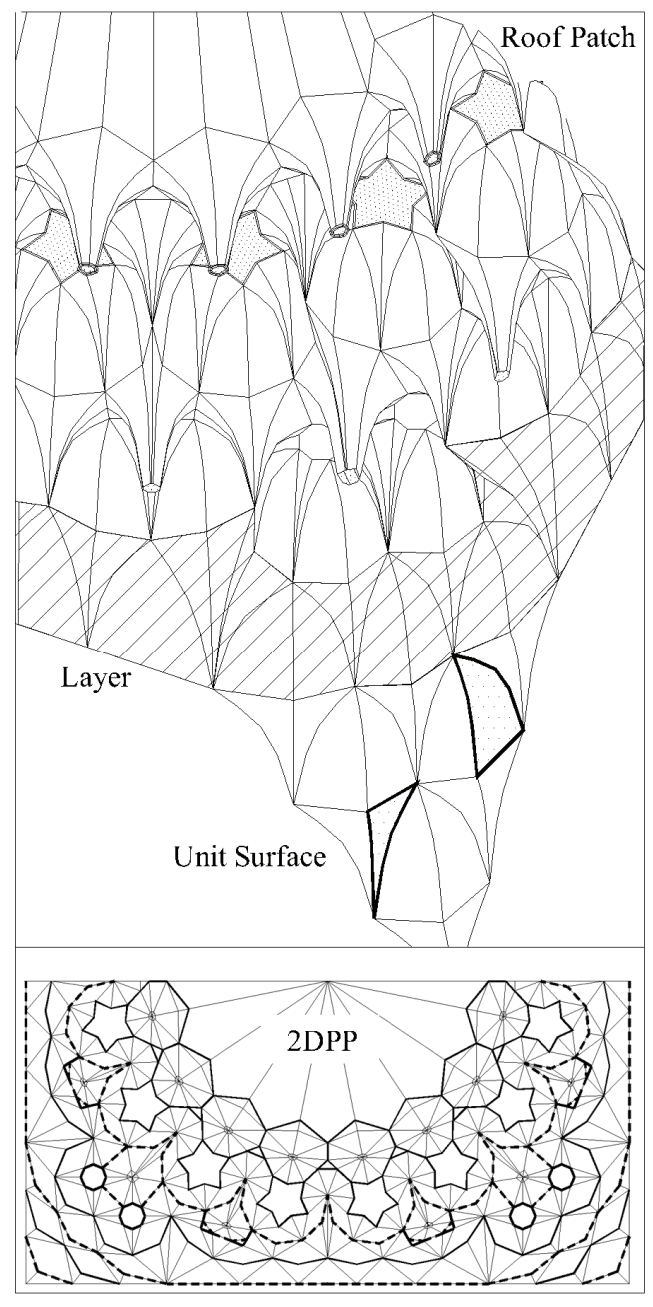

Figure 1: The basic parts of the muqarnas

\section{THE THEORY}

Typology is a system of sorting and could be defined in many ways. I will quote that of William and Ernest Adams.

A typology is a conceptual system made by partitioning a specified field of entities into a comprehensive set of mutually exclusive types, according to a set of common criteria dictated by the purpose of the typologist. Within any typology, each type is a category created by the typologist, into which he can place discrete entities having specific identifying characteristics, to distinguish them from entities having other characteristics, in a way that is meaningful to the purpose of the typology. (Adams, 1991, p. 91)
I also agree on his basic notion that a typology is evaluated in the degree its usefulness. The usefulness sought in this paper is its ability to create 'new forms' out of the 'traditional', and to push the evolution of the form forward. Adams' discussion of typology is in the realm of archaeology but his second chapter is a general discussion of typology that can be applied in any field. There are many architectural typological studies that looked upon typology as a source of creativity, like those of (Rafael, 1978) and (Rossi, 1982, pp. 35-41), but I will try to present my own theory, which is based on agreeing and disagreeing with many aspects of these studies. The only criterion in its evaluation is the degree of its usefulness, for which I will present many projects where it had been used and proved to be useful.

The theory stems from few axioms:

(i) In reality there are no two identical objects. Every object is unique and has special characteristics of its own. No matter how two objects are manufactured to look alike, they will never be identical. They would differ at many levels. Two cars of the same brand, of the same color, with the same specifications are not identical in the real world. They will differ at the micro level. This also applies to natural objects. 'Identical' is a mental concept that cannot be applied in the real world, but is applied in our minds according to our perception of the 'identical' concept.

(ii) For every object we encounter in the real world we build a conceptual type in our minds. Or we include it within a predefined type created from a previous encounter with another object. This predefined type will be altered accordingly. First I will try to explain this process, and then I will provide a definition of the word 'type'.

If we never encounter a 'mug' for example, then for the first mug we see, we will define a mental type that includes only this object. This mental type would differ from a person to another. To describe it, we would state all characteristics we perceived of the object. For some it could be defined as such: 'a cylindrical form open-faced from the top with a side handle.' Others might add 'created from terracotta', 'is red', 'used to drink coffee', and such. All definitions depend on our previous training in observation and in abstraction, and on the level of our indulgence with the object and the way it was presented to us. At this stage all these qualities have only one value for this type which has only one member (we will refer to this quality which has a single value as a 'characteristic'). 
When we encounter another mug with all previous qualities but blue, we would then include it in the previous type which we will alter one of it characteristics (the 'is red') into 'is red or blue'. If we define this quality as 'colour', then it would be a variable and can take any colour we know (we will refer to this quality which we can alter its value as an 'attribute').

If we encounter an object with all these qualities, but with a parallelogram form, than we can include it in our type, but we have to alter the 'cylindrical form' characteristic into an attribute (that might be called 'form'). 'Cylinder' and 'parallelogram' would, thus, be possible values. Defining it this way would enable us to create a new mug with a spherical form. According to above, a type is a mental concept used to refer to one or more objects (or concepts), it has a group of characteristics, and, if it has more than one member, it has also a group of attributes.

To define an object is, thus, declaring its type.

(iii) For every type there are the conscious characteristics that can be stated (as in the previous example), and there is unlimited number of unconscious characteristics (for example the creator, the date of creation, its type of atoms... etc.). Such characteristics can be discovered later to the time the type was created. Thus, it is impossible to have a comprehensive definition of any object.

(iv) Different types can be merged to create a new type. This merging occurs when new characteristics are discovered and sought. For example, if we found a historical building with vertical rectangular windows and vertical subdivisions, then we would define its type of windows as rectangular with vertical subdivision (Figure 2a). If we found another one with vertical rectangular windows but with a semicircle on top, then its type of windows will be defined as such (Figure 2b). Now if it was discovered that these two buildings belonged to the same era and location (a new characteristic), and we want to define the window type of that era, then it would be a rectangular shape with a possible semicircle on top and possible vertical divisions. All windows of the two buildings will be included. Moreover, if we want to design a building on the same spirit but without direct copy from the past, all possible combination (even those not found historically), can apply (Figure 2c). It should be noted here that only the formal attributes are considered; if the cultural aspects are included, some of the above forms maybe excluded and others added.

(v) Accordingly, our definitions (the mental types we create) of objects control all possibilities of their upcoming evolution. Throughout history, wrong definitions hindered the development of so many scientific fields.

(vi) The evolution of a form takes place at two levels. The first is a simple progress that is achieved by suggesting new values for an attribute. For example the material of the Greek entablature, as known today, is stone. In actual historical course, stone is another value for the 'material' attribute which was firstly wood. The second type of evolution is more creative and involves transforming a characteristic into an attribute. For example, an arch was defined to be created according to a single center; this was one of its characteristics. Through history, however, this criterion was turned into an attribute with a value of one. Two, three, and four were new values and pointed arch, three-centered and fourcentered arches were created.

This second type of form evolution is more creative, and requires a new vision of things; it had been applied in history but in a slow unconscious process. To evolve forms we must do this consciously.

The next section will attempt to explain how it was used to evolve the muqarnas form at many levels of research

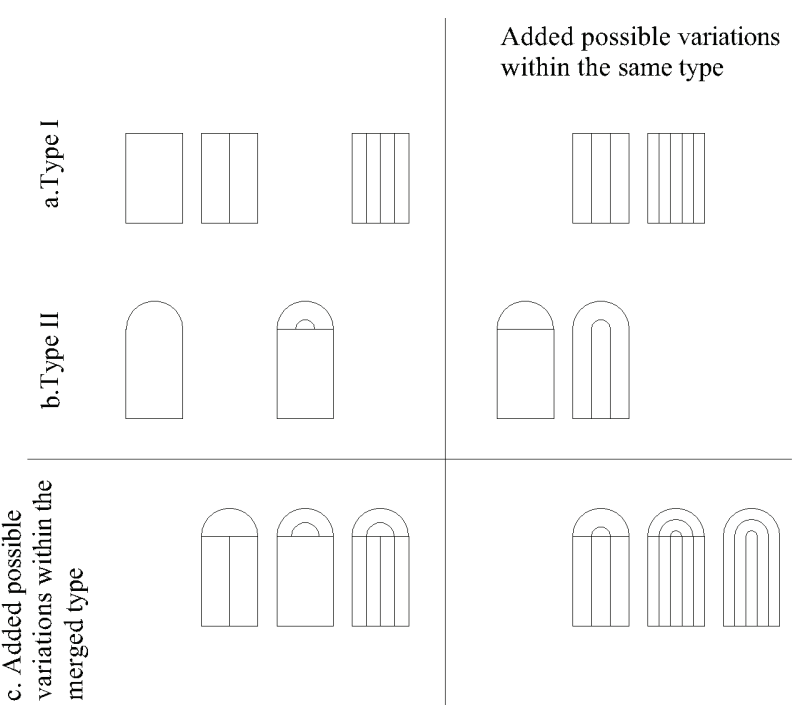

Figure 2: Merging two types to create a new one 


\section{APPLICATIONS IN MUQARNAS}

The above theory was utilised in muqarnas research to attempt creating new evolutions in the form. The resultant forms could be categorised into four groups; plan alteration, layer alternation, adding structural values, and creating new form vision to be seen form both inside and outside.

\subsection{New forms evolving from plan alternation}

This group represents two paths of evolution. First, deregulating the plan, and second altering the plans of the traditional pre-design erecting units.

\subsubsection{Deregulating muqarnas plans}

Throughout history muqarnas forms were built according to two-dimensional pattern plans (2DPPs) as indicated by those found incised on plaster (Harb, 78, pp. 9-10; Yaghan, 2000, p. 77), drawn on parchments (Gülru Necipoğlu, 1995, pp. $3-27$ ), or simply found when a plan of the form is projected on paper. These pattern plans were regular, in many cases had multi-fold symmetry, and with a regular arrangement (liner, radial, or grid) of units, groups of units, and focal points (Yaghan, 2001. pp. 41-45).

This regularity was never stated as a characteristic of muqarnas forms; nevertheless, it was used all the time. New forms were created when this characteristic was turned into an attribute, and 2DPPs were made irregular as another value for regular.

Figure 3 shows a totally irregular 2DPP along with its three-dimensional muqarnas form representing a new vision of muqarnas.

\subsubsection{Altering the traditional pre-designed muqarnas units}

In the western Islamic lands, producing muqarnas forms involved the use of pre-designed units that can be combined into a very wide range of alternatives. The plans of these units were based on shapes of 45-, 90-, 135-, and 67.5- degrees.

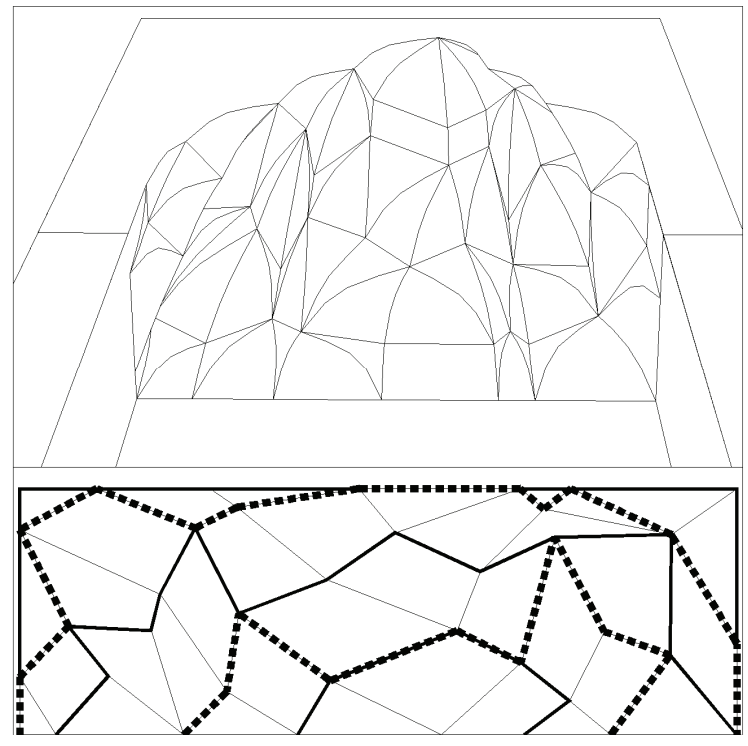

Figure 3: An irregular 2DPP along with its $3 D$ form

These were used to produce muqarnas forms during the Islamic reign in Spain and by the Mudejar artists (Modejar art: the post-Islamic art and architecture built in Spain according to the Muslim architectural practices). They are still in use today in the traditional crafts in Morocco (Yaghan, 2001, pp. 298-301; Puertas, 1993; Paccard, 1980, pp. 280-305). Figure 4 shows the plans and the three-dimensional forms of the generic group of these units according to (Yaghan, 2001, p. 301).
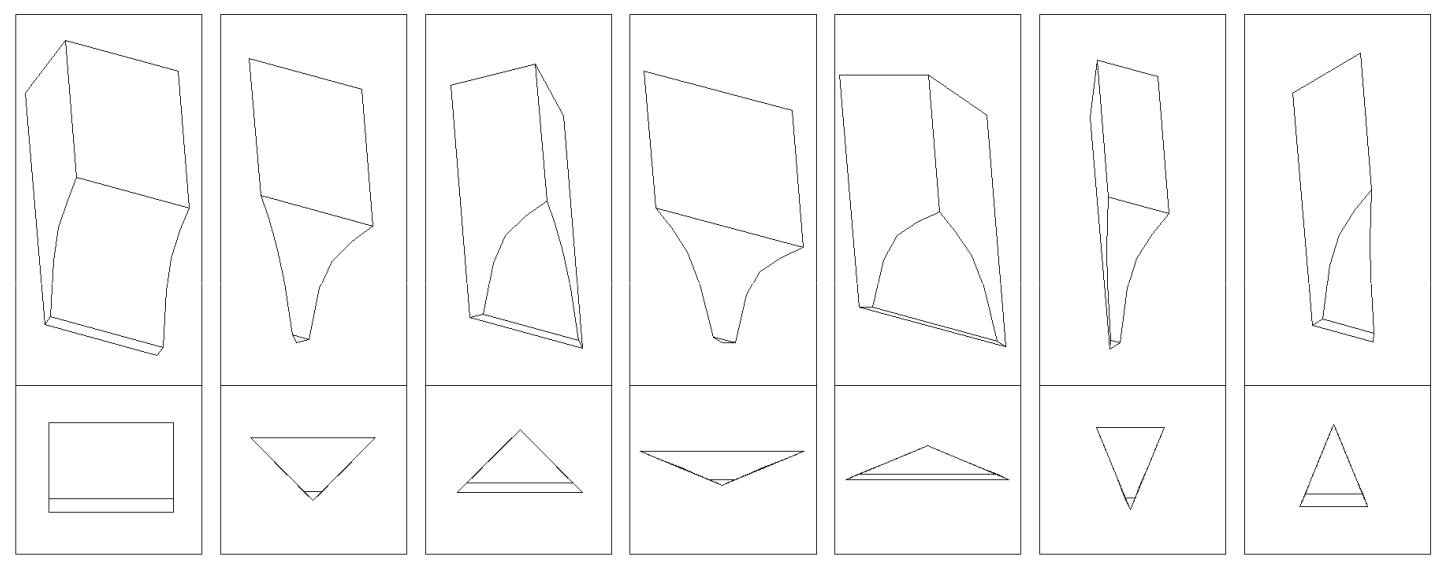

Figure 4: The plans and three-dimensional forms of the generic group of the pre-designed muqarnas units according to (Yaghan, 2001b, p. 301) 
The limitation in the shapes of the plans of the units (which was a characteristic of the units) led to some limitations in their muqarnas forms (Yaghan, $2001 \mathrm{~b}$, p. 306), and the space shapes beneath them had to be squares, rectangles, or pentagons. In order to develop this type of muqarnas the angles of the units' plans were turned into attributes and new values were allowed. In order to do so, a system for defining the angles had to be found. It was synthesised from the historical context of the ribbed domes and the repetitive units which prevailed in the western Islamic lands at the time.

Thus, a new system for generating pre-designed units' plans was suggested (Yaghan, 2001b, p. 311). For any polygon, inscribed inside a circle, a set of pre-designed muqarnas units' plans can be created by, first, joining the centre with the corner and edge-mid points, which would result in two repeated mirrored right-angled triangles, and, second, by creating two rectangles from the sides of these triangles and their hypotenuse. Figure 5 shows the process of synthesising the plans. The three-dimensional forms would be created according to the same traditional process (Yaghan, 2001 b, p. 308). Accordingly new muqarnas forms pre-designed units that can cover any space (triangular, pentagonal ...etc.) can now be created.

Figure 6 shows a muqarnas form covering a pentagonal space created with new pre-designed units from the pentagon and the decagon.
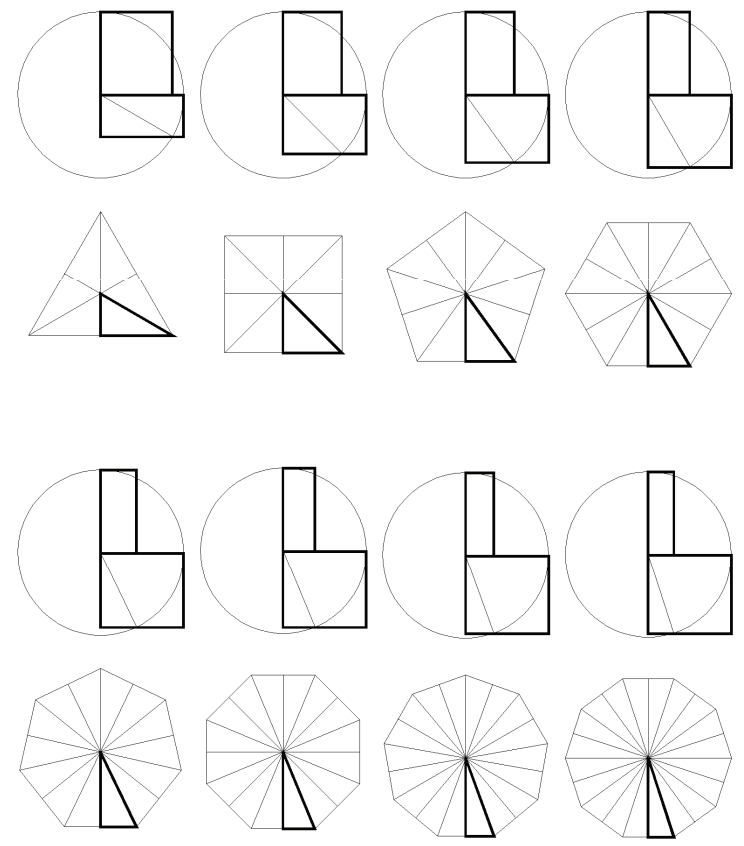

Figure 5: A new system for generating pre-designed units' plan (Yaghan, 2001b, fig.17)
Another evolution (in the simpler approach of the theory, which is adding new values to the attributes) was achieved in new values for the three-dimensional attributes of the single unit.

Figure 7.a shows the basic attributes of the traditional units which are the height, the horizontal joint, the vertical joints, and the curve shape.

Figure 7.b illustrates the effect of giving new values to the curve shape (some values are possible only via the computer programs).

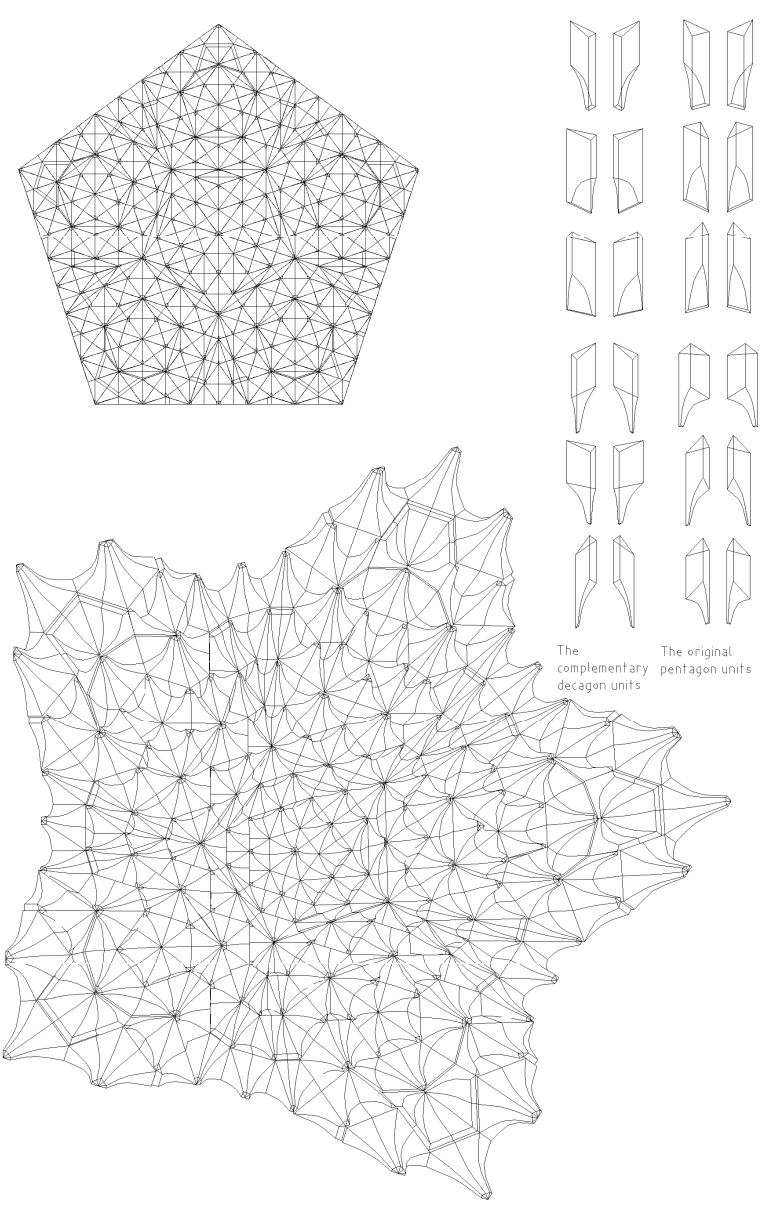

Figure 6: A muqarns covering a pentagonal space (modified from Yaghan, 2001b, fig. 18) 


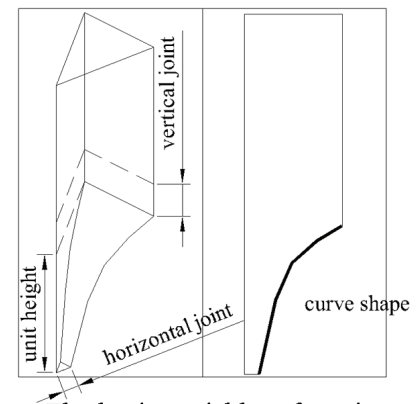

a. The basic variables of a unit

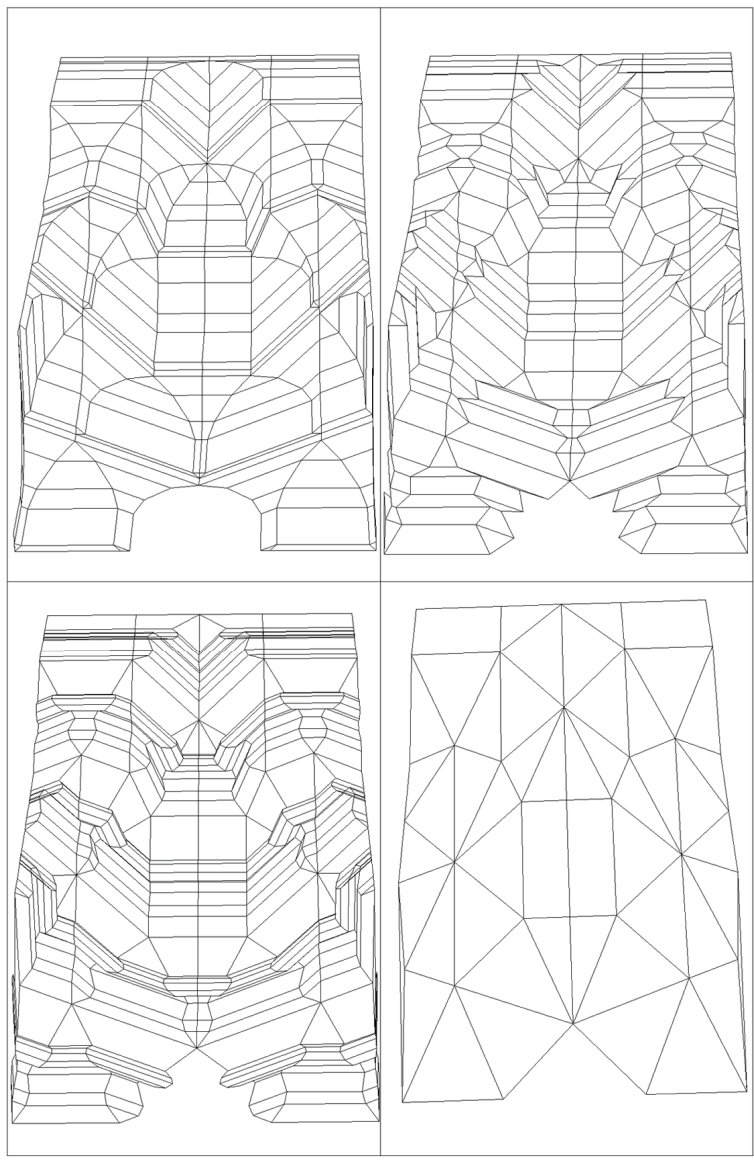

b The effect the curve shape

Figure 7: The basic attributes of the traditional units, and the effect of giving new values to curve shape

\subsection{New forms evolving from layer alternation}

A basic characteristic of any Muqarnas forms is that it is composed of layers. Each layer has baseand top-layer lines that follow the 2DPP and are in their turn regular. The layers, and their layer-line, are always horizontal (Yaghan, 2000, pp. 39-41). This characteristic was turned into an attribute and layer-lines were allowed to be non-horizontal.

Figure 8 shows a new muqarnas form created by altering the horizontality of the layer lines. This example was created in a symmetrical approach, but also non-symmetrical forms can also be created.
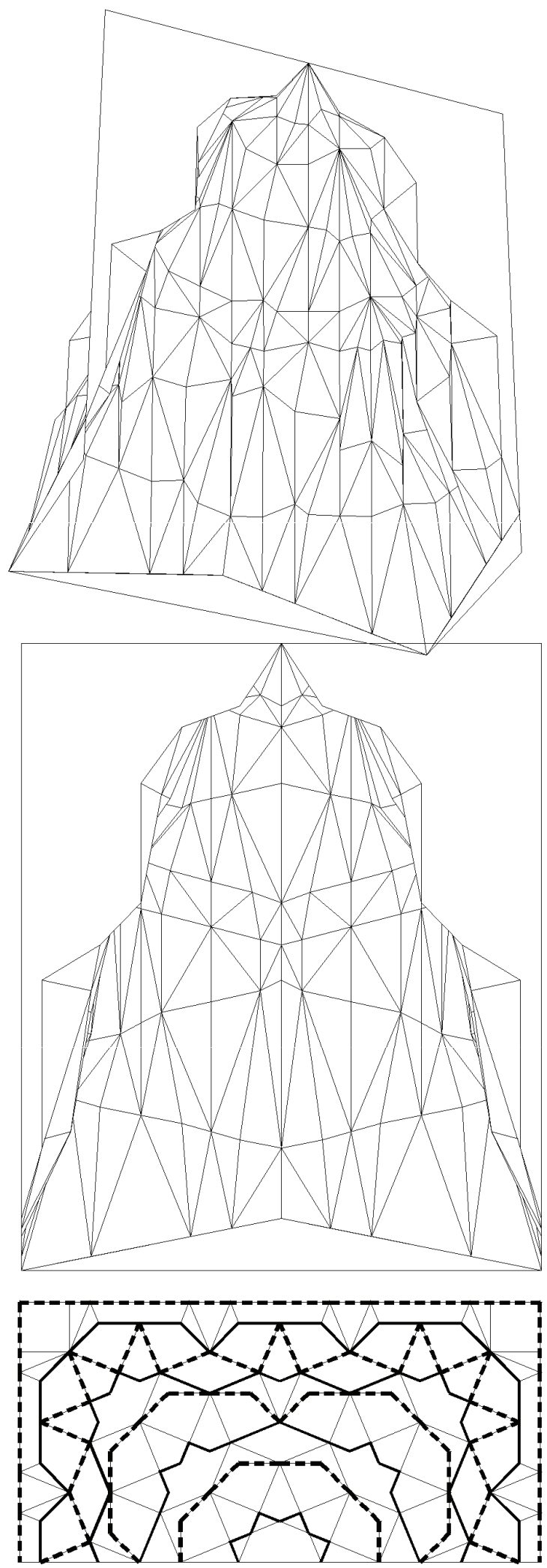

Figure 8: A new muqarnas form with non-horizontal layer-lines (Yaghan, 2001a, figs 77-78) 


\subsection{New forms with structural value}

Although few muqarnas forms had a structural role like in the structural genuine muqarnas domes in Iraq during the 11th to the 13th century (Yaghan, 1998), muqarnas was never a structural tool or necessity. On the contrary the greater number of muqarnas forms were decorative. The predesigned units presented in the previous section were purely decorative, and this was a basic characteristic of them. When this was turned into an attribute and was given a new value (structural necessity), new muqarnas forms were created. The side surfaces of these units were altered and directed towards a single point or a line, and thus all units would support each other and prevent themselves from falling (in a similar concept to the arch voussoirs where the wedged shape of the stones prevent them from falling, but in two directions rather than one) (Yaghan, 2005a).

Accordingly, a line- and point-oriented structural muqarnas forms were created. Figure $9 a$ shows the concept in changing the shape of the unit, and Figure $9 \mathrm{~b}$ shows line- and point-oriented muqarnas forms.

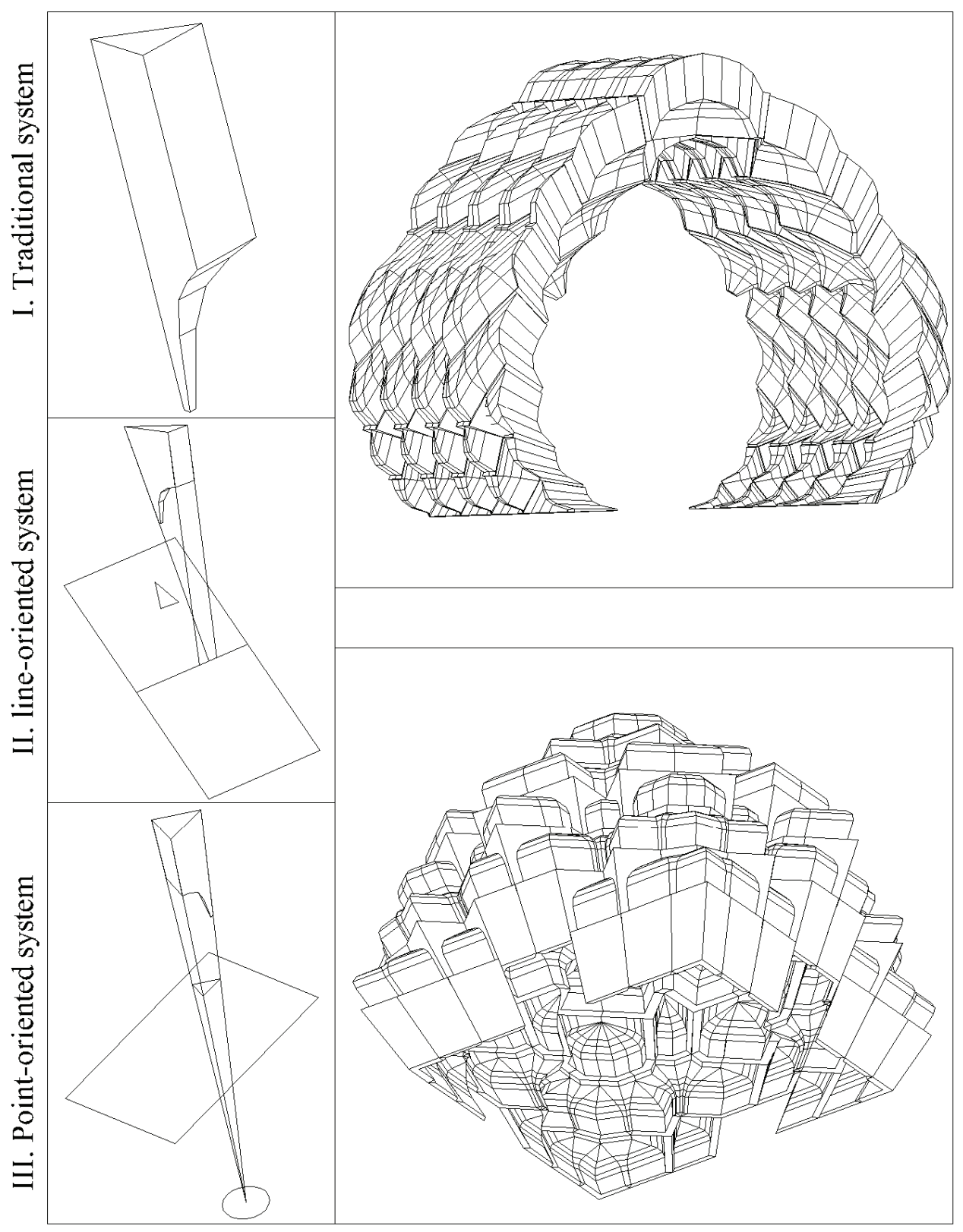

Figure 9: Line- and Point-oriented self-supporting muqarnas 


\subsection{New vision inside-out}

Few early muqarnas forms were 'genuine' (could be seen from inside and out), but their two sides varied greatly and were never the same from (Yaghan, 1998). Muqarnas forms are found to have this characteristic of being seen from one side only (externally or internally). With altering the top of the pre-designed units into reflecting lower curved surface, new muqarnas forms that can be seen internally and externally (genuine muqarnas) were created (Yaghan, 2005a) (Figure 10).

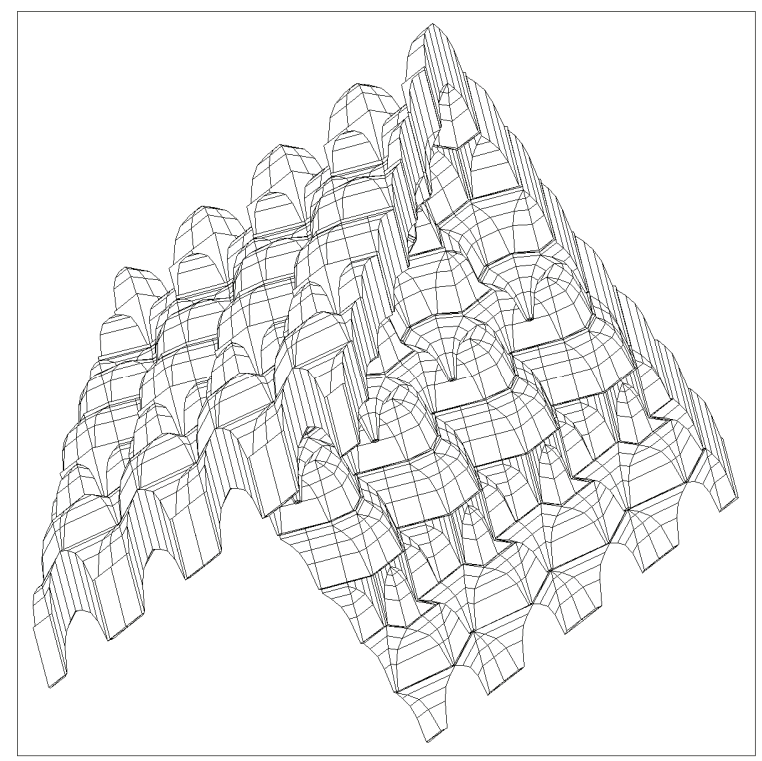

Figure 10: Genuine muqarnas form (seen from inside and outside)

\section{CONCLUSION}

The paper presented the theory behind many muqarans studies that led to the evolution of its form at many levels. It started with an introduction about muqarnas and its role in Islamic architecture. Second, it presented the theory which revolves around typology. Finally, it presented the applications of the theory in the muqarnas field. That included: new forms evolving from plan alternation, new forms evolving from layers alternation, new forms with structural value, and a new vision inside-out of the muqarnas. The paper promotes the use of the theory in other architectural fields.

\section{REFERENCES}

Adams, W. and Adams, E. (1991) Archaeological Typology and Practical Reality. Cambridge University Press, Cambridge.

Rossi, A. (1982). The Architecture of the City, MIT Press, Cambridge MA.

Paccard, A. Mary Guggenheim (translator). (1980) Traditional Islamic Craft in Moroccan Architecture. Vol. 1. Atelier.

Behrens-Abouseif, D. (1993) Mukarnas. In Encyclopaedia of Islam, Vol. VII, pp. 501-506. E. J. Brill, Leiden, the Netherlands.

Fernandez Puertas, A. (1993) Mukarbas In Encyclopaedia of Islam, Vol. VII, pp. 500-501. E.J.Brill, Leiden-New York.

Gülru Necipoğlu, (1995) The Topkapi Scroll Geometry and Ornament in Islamic Architecture. The Getty Center for the History of Art and Humanities, Santa Monica, USA.

Ulrich, H. (1978) Ilkhanidische Stalaktitengewolbe Beitrage zu Entwurf und Bautechnik. Dietrich Reimer Verlag, Berlin

Rafael, M. (1978) On Typology. Oppositions, summer 1978,13 , pp. 22-45.

Yaghan, M. (1998) Structural Genuine Muqarnas Dome, Journal of King Saud University, Architecture and planning, Vol. 10, pp. 17-52.

Yaghan, M. (2000) Decoding the Two-Dimensional Pattern Found at Takht-i Sulayman into ThreeDimensional Muqarnas Forms. Iran, XXXVIII, pp. 77-95.

Yaghan, M. (2001a) The Islamic Architectural Element 'Muqarnas': Definition, Geometrical Analysis, and a Computer Generation System. Phoibos Verlag, Vienna.

Yaghan, M. (2001b) The Muqarnas Pre-Designed Erecting Units: Analysis, Definition of the Generic Set of Units, and a System of Unit-Creation as a New Evolutionary Step. Architectural Science Review, Vol. 44, No. 3, pp. 297-318, Sep. 2001.

Yaghan, M. (2005a) Self-Supporting 'Genuine' Muqarnas Units. Architectural Science Review, Vol. 48, No. 3, pp. 245-263, Sep. 2005.

Yaghan, M. (2005b) Online course on Muqarnas http:// muqarnas.muqarnas.org (1 March 2010) 